\title{
LA Grade A
}

National Cancer Institute

\section{Source}

National Cancer Institute. LA Grade A. NCI Thesaurus. Code C62424.

One or more mucosal breaks no longer than $5 \mathrm{~mm}$, none of which extends between the tops of the mucosal folds. 